\title{
Revisiting the Origin of the Preferential $\pi-\pi$ Stacking Conformation of the (+)-8-Phenylmenthyl Acrylate
}

\author{
Saulo L. Capim, Sidney R. Santana, Boaz G. de Oliveira, Gerd B. Rocha* and \\ Mário L. A. A. Vasconcellos* \\ Departamento de Química, Universidade Federal da Paraíba, Campus I, \\ 58059-900 João Pessoa-PB, Brazil
}

\begin{abstract}
Neste artigo reportamos um estudo teórico objetivando revisitar a origem da conformação $\pi-\pi$ stacking do (+)-acrilato de 8-fenilmentila (2) ser a preferencial. Para isso, calculamos geometrias de mínimo local, freqüências vibracionais, propriedades termoquímicas e deslocamentos químicos de RMN de ${ }^{1} \mathrm{H}$ para 2 e para o composto modelo acrilato de 3-fenilpropila (3) usando vários métodos $a b$ initio e de DFT. Observamos que o funcional MPW1B95 foi o método mais apropriado em explicar os dados experimentais de RMN de ${ }^{1} \mathrm{H}$ nos quais mostram que a conformação stacking de $2(2 S)$ é mais estável que a conformação trans $(2 T)$ e a conformação stacking de $\mathbf{3}(\mathbf{3} S)$ é menos estável que a conformação trans (3T). Após isso, detalhes geométricos e energéticos do complexo intermolecular benzeno...metilacrilato (4) também foram estudados usando o método MPW1B95. A partir dos nossos resultados percebemos que ambos os efeitos, estérico e de dispersão, desempenham papéis chave no equilíbrio conformacional de 2.
\end{abstract}

In this paper we report a theoretical study aiming to revisit the origin of the preferential $\pi-\pi$ stacking conformation of the (+)-8-phenylmentyl acrylate (2). For this, we have applied several DFT and ab initio methods to calculate local minimum geometries, vibrational frequencies, thermochemical properties and ${ }^{1} \mathrm{H}$ NMR chemical shifts for $\mathbf{2}$ and the model compound 3-phenylpropyl acrylate (3). We have observed that the MPW1B95 functional was the most suitable method to explain ${ }^{1} \mathrm{H}$ NMR experimental data which show the stacking conformation of $2(2 S)$ is more stable that trans conformation $(2 T)$ and the stacking conformation of $\mathbf{3}(\mathbf{3 S})$ is less stable that trans conformation (3T). After that, geometrical and energetic features of the intermolecular complex benzene...methylacrylate (4) have also been studied using MPW1B95 method. From our results, we have noticed that both steric and dispersion effects play a key role in the conformational equilibrium of 2.

Keywords: conformational analysis, intramolecular $\pi-\pi$ stacking interactions, MPW1B95 functional, chiral auxiliaries, enantioselective synthesis

\section{Introduction}

Since 1975, when Corey and Ensley ${ }^{1}$ used (+)-8-phenylmenthol (1) (Figure 1) for the preparation of the acrylate derivative (2) for enantioselective synthesis of prostaglandins, compound $\mathbf{1}$ has ranked among the most versatile chiral auxiliary in the toolbox of asymmetric organic synthesis, being especially useful for $\pi$-face-differentiation. ${ }^{2}$ The presence of an aromatic nucleus is a salient feature common to many chiral auxiliaries, particularly those which provide the highest level of stereocontrol. The special stabilization in the stacking conformation $(2 S)$ by

*e-mail:mlaav@quimica.ufpb.br,gbr@quimica.ufpb.br $\pi-\pi$ dispersion interaction between the aromatic and the acrylate groups has emerged as one of the most attractive explanations. ${ }^{3}$ For example, Ulukanli et al..$^{4}$ described the aziridination of compound $\mathbf{2}$ in high diastereoselectivity using 3-acetoxyamino-2-ethylquinazolinone. According to the transition state proposed by Ulukanli et al., ${ }^{4}$ the reaction occurs selectively on the si face of the acrylate moiety of $\mathbf{2}$ due to hindrance of the aromatic benzene ring on the $r$ face (see Scheme 1).

However, up to now there are some questions to be answered: is the attractive dispersion interaction between the phenyl group and the acrylate moiety in $\mathbf{2 S}$ (increasing its relative stability) the only effect which controls the preferential $\pi-\pi$ stacking conformation of $\mathbf{2}$ (Figure 1)? 


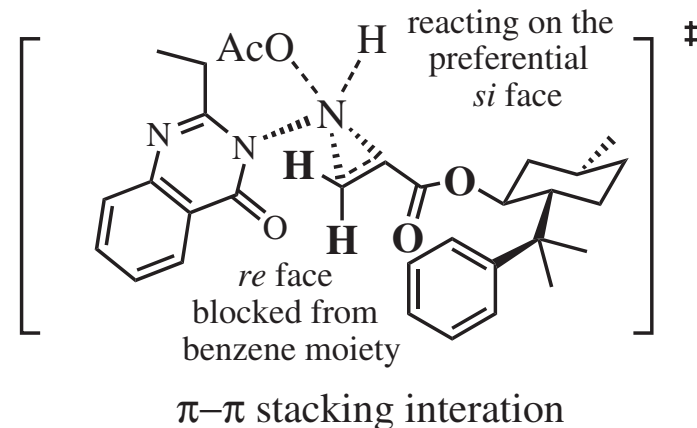

Scheme 1. Transition state of the aziridination of (+)-8-phenylmenthyl acrylate (2) using 3-acetoxyamino-2-ethylquinazolinone.

Could it be the steric repulsion effect, e.g. between one of the methyl groups and the acrylate moiety in $2 T, 5$ (increasing its relative energy) also an important effect to be considered? Or perhaps it is the case that both effects are controlling the preferential $\pi-\pi$ stacking conformation of 2? As far as we know, there are no theoretical studies involving density functional theory (DFT) and ab initio methodologies aiming to evaluate the actual origin of the relative stabilities of $\mathbf{2} S$ and $\mathbf{2} T$ conformations.

A survey of the recent chemical literature reveals an explosion of interest in the theoretical studies of non-covalent intermolecular interactions, specially the $\pi-\pi$ stacking ones. ${ }^{6}$ However, these kinds of studies for intramolecular $\pi-\pi$ stacking interactions, using theoretical methods, are still very lacking. ${ }^{6}$

High-level quantum chemical calculations coupled with large basis sets covering large portions of correlation energy are required to describe accurately the noncovalent dispersion interactions. ${ }^{7-9}$ For large structures or complexes, these high-level quantum chemical calculations cannot be carried out due to the high computational demand. For small or medium molecular structures we can apply second-order Møller-Plesset perturbation theory (MP2), which approximately accounts for uncoupled, two-body electron correlations. Unfortunately, some authors have detected that MP2 combined with an extended basis set tends to overestimate binding in non-covalent interactions. ${ }^{10,11}$ On the other hand, DFT has been used as one of the most efficient theories to estimate non-covalent effects. ${ }^{7-9,12,13}$ Recently, M. Swart et al. ${ }^{14}$ have surprisingly shown that the LSDA functional was the most effective to evaluate $\pi-\pi$ stacking interaction, compared with others DFT methods, including the KT1 and KT2. At the same time, Moa et al. ${ }^{15}$ have performed DFT single-point calculations on the X-ray geometry of the quinone-hydroquinone (quinhydrone) intermolecular complex, and they were able to reproduce the experimental enthalpy when they used the method MPW1B95/6-311++G(2d,2p) with Cartesian $d$ function for polarization atomic orbitals.

Then, in connection to our interests on developing new chiral auxiliaries, ${ }^{16-20}$ synthesis $^{21}$ and conformational studies $^{22}$ of the new aromatic acrylate compounds to act as drugs, ${ }^{23-25}$ we present in this paper a theoretical study involving DFT and $a b$ initio methodologies aiming: (i) to discover which method is more suitable to estimate $\pi-\pi$ stacking interactions between aromatic and acrylate moieties for medium-size systems and (ii) to evaluate if the intramolecular $\pi-\pi$ stacking interactions really are the only effects that controls the conformation of (+)-8-phenylmenthyl acrylate (2).

\section{Computational Details}

First, we have used Hartree Fock (HF), MPW1B95, ${ }^{26}$ M06, ${ }^{27}$ M06-2X, ${ }^{27}$ B $97 \mathrm{D}^{28}$ (this functional includes dispersion corrections) and MP2 in order to find the gas phase local minima of $\mathbf{2} S, \mathbf{2} T, \mathbf{3} S$ and $\mathbf{3} T$ (Figure 2). For this step, we have used the basis set $6-311++\mathrm{G}(2 \mathrm{~d}, 2 \mathrm{p})$ considering Cartesian $d$ functions for polarization (6d opition in Gaussian input) for all calculations. All local minimum geometries were fully optimized without any symmetry constraints. After that, we have characterized each local minimum geometry by normal coordinate analysis at the corresponding theoretical level.

Next, the optimized geometries obtained from MPW1B95 were used on several single point energy calculations on MPWB1K, ${ }^{26} \mathrm{MPW} 1 \mathrm{~B} 95,{ }^{26} \mathrm{M} 06,{ }^{27}$ M06-2X,,${ }^{27}$ B97D, ${ }^{28}$ LSDA, ${ }^{29}$ B3LYP, ${ }^{30,31}$ B3LYP-D, ${ }^{32}$ B3PW91, ${ }^{33}$ MPW1PW91, ${ }^{34} \mathrm{HCTH},{ }^{35}$ PBE1PBE, ${ }^{36.37}$ Hartree-Fock, second- and third-order Møller-Plesset perturbation theory (MP2 and MP3), Spin-component scaling MP2 (SCS-MP2) ${ }^{38}$ and Spin-component scaling MP3 (SCS-MP3) 39 methodologies.

These calculations were carried out using GAUSSIAN $2003,{ }^{40}$ GAUSSIAN $2009^{41}$ and ORCA (only for B3LYP-D). ${ }^{42}$

In order to verify the eficiency of MPW1B95 functional to predict the conformers for molecules 2 and $\mathbf{3}$, we have performed some calculation of ${ }^{1} \mathrm{H}$ NMR chemical shifts using gauge invariant atomic orbital GIAO methodology ${ }^{43}$ on the MPW1B95 local minimum geometries of all studied conformers, including solvent effects through $\mathrm{PCM}^{44}$ methodology considering chloroform as solvent. ${ }^{1} \mathrm{H}$ NMR chemical shifts calculation for Tetramethyl silane, TMS, considered as the reference, were carried out using the same method, basis set and PCM conditions. 
<smiles>CC1CCC(C(C)(C)c2ccccc2)C(O)C1</smiles>

1<smiles>C=CC(=O)OC1CC(C)CC[C@H]1C(C)(C)c1ccccc1</smiles>

2<smiles>C=CC(=O)OCCCc1ccccc1</smiles>

3

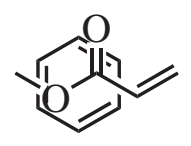

4

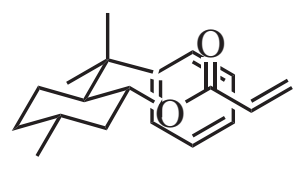

Stacking $(S)$

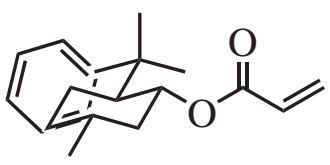

Trans $(T)$

$2 T$<smiles>C=CC(=O)OCC1Cc2ccccc21</smiles>

Trans $(T)$

\section{Stacking $(S)$}

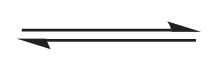

$3 S$

Figure 1. Structures for calculated conformations.

Finally, for the non-covalent complex 4, we have performed calculations (geometry optimization and frequencies) using MPW1B95 and the same basis set with and without the counterpoise (CP) corrections for basis set superposition error (BSSE). ${ }^{45,46}$

\section{Results and Discussion}

First, we will qualitatively describe geometrical features for the considered conformations of compounds $\mathbf{2}$ and $\mathbf{3}$ (see Figure 2) in order to simplify our discussions.

For compound 2 we have two clear situations: $(i)$ in the conformation $2 S$ the phenyl group make $\pi-\pi$ stacking interaction with the methyl acrylate group while one of the benzylic methyl group is located in trans position, (ii) in the conformation $2 T$ we have the phenyl group in trans position while one of the benzylic methyl is located interacting with the methyl acrylate group.

For compound $\mathbf{3}$ the situation is almost the same. The difference between conformations $\mathbf{3 S}$ and $\mathbf{3} T$ is that in benzylic positions we now have hydrogen atoms, which present a smaller molecular volume.
It is important to notice that previous experimental data obtained by ${ }^{1} \mathrm{H}$ NMR spectra ${ }^{1,47,48}$ (all spectra were obtained in deuterated chloroform and at room temperature) confirms that the $2 S$ conformation is more stable than the $2 T$ on (+)-8-phenylmentyl acrylate (2) and, the $\mathbf{3} T$ conformation is more stable than $3 S$ on 3-phenylpropyl acrylate (3).

In Figure 3 and table 1 we present the comparison between the ${ }^{1} \mathrm{H}$ NMR data for the hydrogen atoms $\mathrm{H}^{1}, \mathrm{H}^{2}$ and $\mathrm{H}^{3}$ in methyl acrylate (5), ${ }^{47}$ 3-phenylpropyl acrylate ${ }^{48}$ (3) and (+)-8-phenylmenthyl acrylate (2). ${ }^{1}$ From these experimental data it is possible to point out which conformation is more stable for compounds $\mathbf{2}$ and $\mathbf{3}$.

We can note in table 1 that there is no significant shielding effect on $\mathrm{H}^{1}, \mathrm{H}^{2}$ and $\mathrm{H}^{3}$ in $\mathbf{3}$ when compared with the corresponding hydrogen $\mathrm{H}^{1}, \mathrm{H}^{2}$ and $\mathrm{H}^{3}$ in $\mathbf{5}$ $\left(\Delta \delta=0.03\right.$ ppm for $\mathrm{H}^{1} ; 0.01$ for $\mathrm{H}^{2}$ and 0.05 for $\left.\mathrm{H}^{3}\right)$. These data confirm that the conformation $3 T$ is more stable than $3 S$ on this equilibrium. Note that in the conformation $3 S$, the hydrogen atoms $\mathrm{H}^{1}, \mathrm{H}^{2}$ and $\mathrm{H}^{3}$ are positioned in the anisotropic shielding of the aromatic ring. So, if the conformation $3 S$ was the most stable, we would expect 


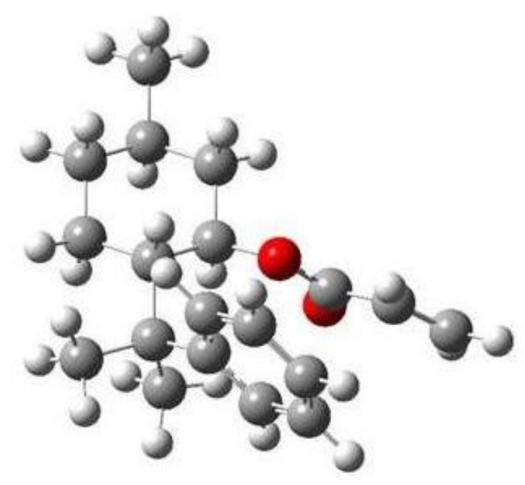

$2 S$

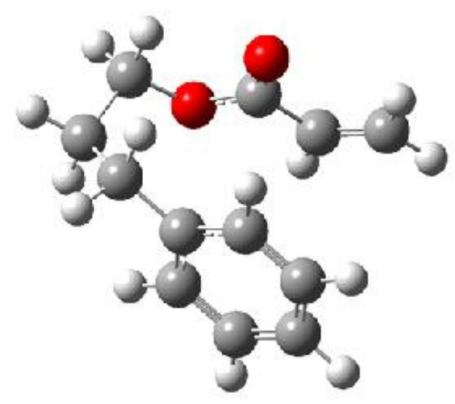

$3 S$

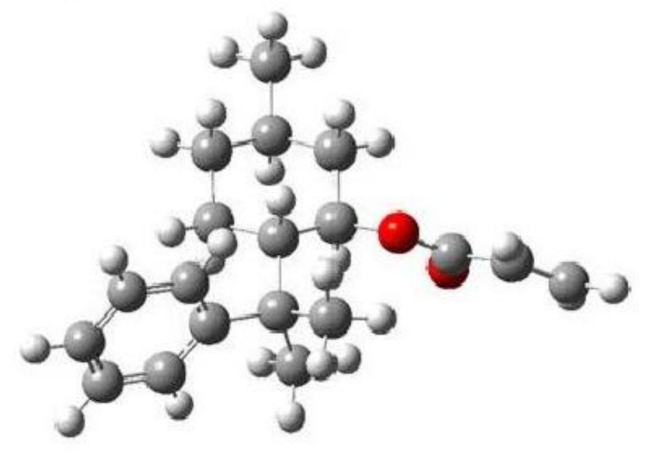

$2 T$

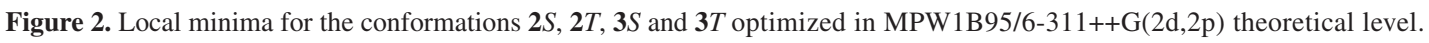<smiles></smiles>

Figure 3. Representative structure for acrylate derivative $\mathbf{2 , 3}$ and 5 .

Table 1. $1 \mathrm{H}$ NMR data (in $\delta \mathrm{ppm})$ to methyl acrylate $\left(\mathrm{R}=\mathrm{CH}_{3}\right),{ }^{34}$ 3-phenylpropylacrylate ( $\mathrm{R}=3$-phenylpropyl $)^{35}$ and $(+)$-8-phenylmenthol acrylate $(\mathrm{R}=(+)-8 \text {-phenylmenthyl })^{1}$

\begin{tabular}{llccc}
\hline Entry & $\mathrm{R}$ & $\mathrm{H}^{1}$ & $\mathrm{H}^{2}$ & $\mathrm{H}^{3}$ \\
\hline 1 & methyl (5) & 6.13 & 6.40 & 5.82 \\
2 & 3-phenylpropyl (3) & 6.10 & 6.39 & 5.77 \\
3 & (+)-8-phenylmenthyl (2) & 5.59 & 6.01 & 5.57 \\
\hline
\end{tabular}

the corresponding signals of $\mathrm{H}^{1}, \mathrm{H}^{2}$ and $\mathrm{H}^{3}$ at higher field, which does not occur.

On the other hand, in the same Table 1, we observed an important shielding effect on the hydrogen atoms $\mathrm{H}^{1}, \mathrm{H}^{2}$ and $\mathrm{H}^{3}$ in 2 compared with the corresponding hydrogen atoms $\mathrm{H}^{1}, \mathrm{H}^{2}$ and $\mathrm{H}^{3}$ in $\mathbf{5}\left(\Delta \delta=0.46\right.$ ppm for $\mathrm{H}^{1} ; 0.39$ for $\mathrm{H}^{2}$ and 0.25 for $\left.\mathrm{H}^{3}\right)$. These data confirm that the conformation $2 S$ is more stable that $\mathbf{2} T$ on this equilibrium. We can note in Figure 2 that $\mathrm{H}^{1}, \mathrm{H}^{2}$ and $\mathrm{H}^{3}$ in $2 S$ are disposed in anisotropic shielding of the aromatic ring, modifying the corresponding signals to higher field.

As can be seen from Figure 2, there are no steric effects in $\mathbf{3 T}$ between the benzylic and acrylate moieties due to the existence of the two hydrogen atoms in benzylic position. Thus, we have selected the molecule 3-phenylpropylacrylate (3) as a good model to indirectly evaluate the $\pi-\pi$ stacking effect without the presence of steric effects observed in $\mathbf{2}$. From this point of view, an efficient theoretical method has to corroborate these experimental data.

Initially, we have performed geometry optimizations for the ground states of the conformers $2 T, 2 S$ using $\mathrm{HF}$ method with the basis set $6-311++\mathrm{G}(2 \mathrm{~d}, 2 \mathrm{p})$ considering Cartesian $d$ functions for polarization. We have found $\Delta \varepsilon_{2 \mathrm{~S}-2 \mathrm{~T}}=0.00 \mathrm{kcal} \mathrm{mol}^{-1}$ for relative total energy for these conformations. This finding confirms that the HartreeFock method underestimate the $\pi-\pi$ stacking interaction, in discordance to the ${ }^{1} \mathrm{H}$ NMR data which show the $2 S$ conformation is more stable than $2 T$. This result was already expected since the $a b$ initio Hartree-Fock method does not consider electron correlation and it cannot accurately 
measure the $\pi-\pi$ stacking interactions. Thus, this method is more appropriate to evaluate the steric effect contributions than $\pi-\pi$ stacking.

Then we have performed geometry optimizations for the ground states of conformers $3 T, 3 S$ using MP2 method and the same basis set. We have found $\Delta \varepsilon_{3 \mathrm{~S}-3 \mathrm{~T}}=-2.73 \mathrm{kcal} \mathrm{mol}^{-1}$ for the relative total energy for these conformations. This finding also confirms that the MP2 method overestimate the $\pi-\pi$ stacking interaction, in discordance to the ${ }^{1} \mathrm{H}$ NMR data which show the $\mathbf{3 T}$ conformation is more stable than $\mathbf{3 S}$.

As a preliminary conclusion, neither Hartree-Fock nor MP2 are good methods to study the conformational equilibria for these compounds.

On these grounds, we have decided to investigate the efficiency of some recent DFT methods to describe the conformational equilibria for the molecules $\mathbf{2}$ and $\mathbf{3}$.

So, we have used the DFT methods MPW1B95, M06, M06-2X and B97D with the same basis set to find the ground state minima for $\mathbf{2 T}, \mathbf{2} S, \mathbf{3 T}$ and $\mathbf{3} S$ conformations.

Table 2 shows gas phase relative total energies $(\Delta \varepsilon)$, gas phase relative total energies including thermal corrections $\left(\Delta \varepsilon^{\text {thermal }}\right)$ and gas phase relative Gibbs energy $\left(\Delta \mathrm{G}^{\circ}, \mathrm{T}=298.15 \mathrm{~K}\right.$ and $\left.\mathrm{p}=1.0 \mathrm{~atm}\right)$ to (+)-8-phenylmenthyl acrylate (2) trans $(2 T)$ and stacking (2S) conformations, and to 3-phenylpropylacrylate (3) trans (3T) and stacking $(3 S)$ conformation (values in $\mathrm{kcal} \mathrm{mol}^{-1}$ ) using the following DFT methods: MPW1B95, M06, M06-2X and B97D. Table 2 still shows the relative conformational populations (in percentage) corresponding to $\mathbf{3 T} \rightleftharpoons 3 S$ inter-conversion equilibrium. Conformational equilibrium population [3T] can be evaluated from the equilibrium constant expression using the well-known equation (equation 1).

$$
[3 \mathrm{~T}]=\frac{1}{1+\exp \left(-\Delta G_{3 \mathrm{~S}-3 \mathrm{~T}} / R T\right)}
$$

The conformational equilibrium population for $\mathbf{3 S}$ can be easily obtained keeping in mind that $[3 S]=1-[3 T]$.

Negative values for $\Delta \varepsilon, \Delta \varepsilon^{\text {thermal }}$ and $\Delta \mathrm{G}$ properties indicate that the conformation stacking $(S)$ is preferable to the corresponding trans $(T)$ conformation and the positive one indicate the trans conformation $(T)$ as the preferable in such equilibrium.

From both calculated $\Delta \varepsilon, \Delta \varepsilon^{\text {thermal }}$ results it can be seen that the MPW1B95 is the only DFT method capable to correctly predict the relative stability between the studied conformations of molecules $\mathbf{2}$ and $\mathbf{3}$. Indeed, this theoretical method predicts that the $2 S$ is the most stable conformer in the conformational equilibrium for 2 and $\mathbf{3} T$ is the most stable conformer in the conformational equilibrium for $\mathbf{3}$, corresponding to negative $\Delta \varepsilon_{2 S-2 T}$ and $\Delta \varepsilon_{2 S-2 T}^{\text {thermal }}$ and positive $\Delta \varepsilon_{3 S-3 T}$ and $\Delta \varepsilon_{3 S-3 T}^{\text {thermal }}$ values.

Our results for gas phase relative Gibbs energies show that the M06 and B97D methods incorrectly predict the conformational equilibrium for the molecule $2\left(\Delta \mathrm{G}_{2 S-2 T}>0\right)$, indicating a lacking of $\pi-\pi$ stacking interaction on its conformational equilibrium in contrast to ${ }^{1} \mathrm{H}$ NMR experimental values shown in Table 1.

Based in the results for Gibbs energies, both DFT methods, M06-2X and MPW1B95 correctly predict the conformational equilibria for compounds 2 and $3\left(\Delta \mathrm{G}_{2 S-2 T}<0\right.$ and $\left.\Delta \mathrm{G}_{3 S-3 T}>0\right)$. However, the value of $\Delta \mathrm{G}_{3 S-3 T}=+0.72 \mathrm{kcal} \mathrm{mol}^{-1}$ calculated using M06-2X method results in the equilibrium population for $\mathbf{3 S}$ of $22.88 \%$. Considering this population on the conformational equilibrium of the molecule $3,{ }^{1} \mathrm{H}$ NMR data through its anisotropic shielding would show the existence of stacking conformation and this evidence is not observed from the data presented in Table 1. On the other hand, MPW1B95 predicts $\Delta \mathrm{G}_{3 S-3 T}=+4.41 \mathrm{kcal} \mathrm{mol}^{-1}$, corresponding to $[3 T]=99.94 \%$ for the trans conformation of this molecule. These results are fully consistent with the experimental observations: a complete lacking of anisotropic shielding in the ${ }^{1} \mathrm{H}$ NMR spectra of $\mathbf{3}$, as we can see in Table 1 .

From these results, we have considered the MPW1B95 method to be the most efficient in correctly describing conformational equilibria of molecules $\mathbf{2}$ and $\mathbf{3}$. For this reason, on the following steps of our study we have decided to verify which methods produce gas phase relative total energies for $\mathbf{2}$ and $\mathbf{3}$ conformers in accordance with experimental data. So, we have carried out single

Table 2. Calculated gas phase relative total energies $(\Delta \varepsilon)$, gas phase relative total energies including thermal corrections $\left(\Delta \varepsilon^{\text {thermal }}\right)$ and gas phase relative Gibbs energy $(\Delta \mathrm{G}, \mathrm{T}=298.15 \mathrm{~K}$ and $\mathrm{p}=1.0 \mathrm{~atm})$, all in $\mathrm{kcal} \mathrm{mol}^{-1}$, for $\mathbf{2 S}-\mathbf{2} T$ and $\mathbf{3 S}-\mathbf{3} T$ conformers and the relative conformational population (in percentage) for $\mathbf{3} S \mathbf{- 3} T$ conformers

\begin{tabular}{lcccccccc}
\hline Method & $\Delta \varepsilon_{2 S-2 T}$ & $\Delta \varepsilon_{3 S-3 T}$ & $\Delta \varepsilon_{2 S-2 T}^{\text {thermal }}$ & $\Delta \varepsilon_{3 S-3 T}^{\text {thermal }}$ & $\Delta \mathrm{G}_{2 S-2 T}$ & $\Delta \mathrm{G}_{3 S-3 T}$ & $\%[3 S]$ & $\%[3 T]$ \\
\hline MPW1B95 & -0.59 & +1.24 & -0.63 & +1.55 & -0.39 & +4.41 & 0.06 & 99.94 \\
M06 & -1.45 & -0.67 & -1.02 & -0.68 & +0.22 & +1.27 & 10.49 & 89.51 \\
M06-2X & -1.46 & -0.82 & -1.49 & -1.04 & -0.97 & +0.72 & 22.88 & 77.12 \\
B97D & -1.55 & -0.72 & -1.26 & -0.68 & +0.16 & +0.27 & 38.80 & 61.20 \\
\hline
\end{tabular}


point energy calculation using MPW1B95 ground state geometries.

This same strategy was carried out by Swart et al..$^{14}$ and Moa et al. ${ }^{15}$ where they have used a theoretically predicted conformation from a reference method in order to evaluate several different computational methods performing single point calculations.

In Table 3 we present gas phase relative total energies obtained from single point calculations to $2 T$ and $2 S$ $\left(\Delta \varepsilon_{2 S-2 T}^{S P}\right)$, and to $3 T$ and $\mathbf{3} S\left(\Delta \varepsilon_{3 S-3 T}^{S P}\right)$ considering several $a b$ initio and DFT methods.

Table 3. Single point gas phase relative total energies $\left(\Delta \varepsilon^{S P}\right)$ (in kcal mol $\left.{ }^{-1}\right)$ for $\mathbf{2} S-\mathbf{2} T$ and $\mathbf{3} S-\mathbf{3} T$ conformers using several methodologies calculated at the MPW1B95/6-311++G(2d,2p) minimum geometries

\begin{tabular}{llll}
\hline Entry & Method & $\Delta \varepsilon_{2 S-2 T}^{S P}$ & $\Delta \varepsilon_{3 S-3 T}^{S P}$ \\
\hline 1 & HF & +0.50 & +5.74 \\
2 & MP2 & -1.89 & -2.40 \\
3 & SCS-MP2 & -1.38 & -0.85 \\
4 & MP3 & -0.93 & +0.34 \\
5 & SCS-MP3 & -1.16 & -0.17 \\
6 & LSDA & -0.96 & -1.26 \\
7 & B3LYP & +0.42 & +4.19 \\
8 & B3LYP-D & -1.29 & -0.61 \\
9 & B3PW91 & +0.35 & +4.08 \\
10 & HCTH & +0.42 & +4.80 \\
11 & MW1PW91 & +0.16 & +3.48 \\
12 & PBE1PBE & -0.06 & +2.84 \\
13 & MPWB1K & -0.70 & +0.98 \\
14 & MPW1B95 & -0.59 & +1.24 \\
15 & M06 & -1.21 & -0.63 \\
16 & M06-2X & -1.30 & -0.53 \\
17 & B97D & -1.33 & -0.78 \\
\hline & & &
\end{tabular}

In Table 3 we can observe that HF method predicts total energy for $3 T 5.74 \mathrm{kcal} \mathrm{mol}^{-1}$ lower than $3 S$ (entry 1). On the other hand, $2 T$ and $2 S$ conformations have similar energies $\left(\Delta \varepsilon_{2 S-2 T}^{S P}=+0.50 \mathrm{kcal} \mathrm{mol}^{-1}\right)$. These results indicate that there is no steric effect between the benzylic hydrogen atoms and the acrylate moiety on $\mathbf{3} T$ conformation (see Figure 2). Differently, there is a steric effect between one of the benzylic methyl groups and the acrylate moiety on the $2 T$ conformation and a steric effect between phenyl and acrylate groups in the $2 S$ conformation. So, considering only the steric effects, the energies of $\mathbf{2} T$ and $\mathbf{2} S$ are almost equal. Thus, any method capable to catch $\pi-\pi$ stacking interaction effects should indicate more stability for the $2 S$ than $2 T$.

The DFT methods: LSDA, B3LYP-D, MPW1BK, MPW1B95, M06, M06-2X and B97D indicates that $2 S$ is lower in energy than $2 T$ (see Table 3 ). The ab initio methods MP2, MP3 and their spin-component-correction versions (SCS-MP2 and SCS-MP3) also indicate conformation $2 S$ as the most stable. The DFT methods B3LYP, B3PW91, HCTH and MPW1PW91 were not efficient to estimate $\pi-\pi$ stacking interaction on $\mathbf{2}$.

Differently from the analysis for 2, LSDA, MP2, B97D and B3LYP-D methods show erroneously that the conformation $\mathbf{3 S}$ is more stable than $\mathbf{3} T$. Surprisingly, spin-component-correction versions of both MP2 and MP3 erroneously predicted conformation $3 S$ as the most stable. Since ${ }^{1}$ H NMR experimental data in Table 1 confirms that conformation $\mathbf{3 S}$ is not more stable than $\mathbf{3} T$ on the equilibrium, this evidence points out that LSDA, B3LYP-D, B97D, MP2, SCS-MP2 and SCS-MP3 methods are overestimating the $\pi-\pi$ stacking effect in this case.

In fact, as reported by Moa et al. ${ }^{15}$ the Truhlar's DFT methods MPWB1K and MPW1B95 were efficient methods to count the contribution of the $\pi-\pi$ stacking effects for compounds $\mathbf{2}$ and $\mathbf{3}$. The same results were observed when we used MP3 method to calculate gas phase relative total energy. However, MP3 calculations for large molecules are of prohibitive computational expense.

Calculation of NMR chemical shifts can be used to bring forth more information about conformational equilibria for compounds $\mathbf{2}$ and $\mathbf{3}$.

For this, we have carried out proton chemical shift calculations using gauge invariant atomic orbital (GIAO) methodology ${ }^{43}$ and MPW1B95 gas phase ground state geometries considering solvent effects through PCM model. ${ }^{44}$ These results are presented in Table 4 . The hydrogen atoms shown in table 4 are the same highlighted in Figure 3 and their experimental ${ }^{1} \mathrm{H}$ NMR chemical shifts data are in Table 1.

Table 4. Predicted ${ }^{1} \mathrm{H}$ NMR chemical shifts (in ppm) for $2 T, 2 S, 3 T$ and $3 S$ conformers using GIAO MPW1B95/6-311++G(2d,2p) and PCM continuum model (the solvent was set as chloroform). The hydrogen atoms shown in this table are the same as shown in Table 1 and Figure 3

\begin{tabular}{lcccc}
\hline Entry & Conformer & $\mathrm{H}^{1}$ & $\mathrm{H}^{2}$ & $\mathrm{H}^{3}$ \\
\hline 1 & $2 S$ & 5.42 & 7.05 & 6.13 \\
2 & $\mathbf{2 T}$ & 6.77 & 7.27 & 6.45 \\
3 & $3 S$ & 5.51 & 6.85 & 5.87 \\
4 & $\mathbf{3 T}$ & 6.70 & 7.30 & 6.40 \\
\hline
\end{tabular}

A comparison between the predicted chemical shifts and the corresponding experimental ones (respectively, Table 4 and Table 1) show that, despite this non quantitative concordance, we can see the same trends between these data. As it should be expected, all hydrogen atoms for conformation $2 S$ become more shielded than the corresponding ones in 
conformation $2 T$. This same evidence could be observed for the hydrogen atoms of the molecule $\mathbf{3}$.

In a last step, we have decided to predict the minimum geometry of the benzene...methyl-acrylate complex 4 (Figure 4 ) in order to measure the $\pi-\pi$ stacking without steric interferences. For this calculation we have used MPW1B95/6-311G++(2d,2p) (with Cartesian $d$ functions for polarization atomic orbitals) which was the best theoretical method to study these compounds. In this part, our goal was to accurately measure the total formation energy $\left(\Delta \mathrm{E}^{\mathrm{cs}}\right)$ for this complex where the benzene and methyl acrylate are in parallel position to each other, as occurs in $2 S$.

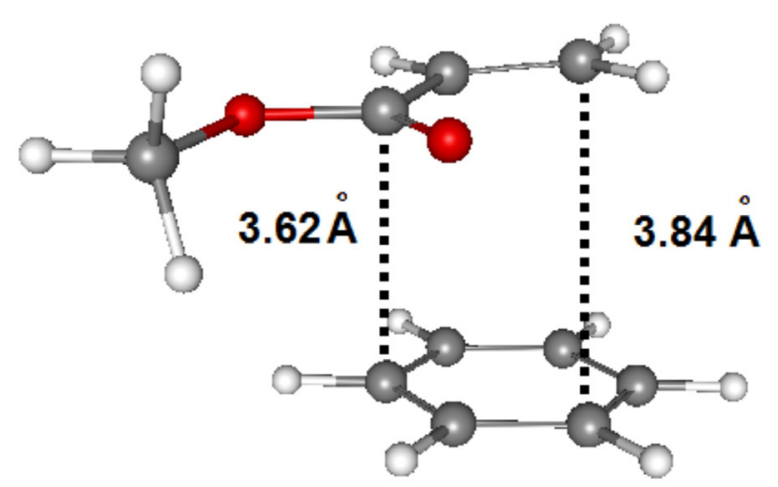

Figure 4. Optimized geometry of the benzene $\cdots$ methyl-acrylate complex 4 using MPW1B95/6-311++G(2d,2p) level of theory.

Note that in complex 4 there are no relevant steric interactions such as the ones in $\mathbf{2}$, so the calculated value of the $\Delta \mathrm{E}^{\mathrm{cs}}$ serve as a good estimation to the dispersion effects that occur in the conformation $2 S$.

The calculated $\pi-\pi$ stacking energy $\Delta \mathrm{E}^{\mathrm{cs}}$ for this complex 4 (Figure 4) was $-1.30 \mathrm{kcal} \mathrm{mol}^{-1}\left(-0.95 \mathrm{kcal} \mathrm{mol}^{-1}\right.$, considering the BSSE correction $\left.=0.35 \mathrm{kcal} \mathrm{mol}^{-1}\right)^{49}$ (Table 5). Considering the relative total energies of all conformers of $\mathbf{2}$ and $\mathbf{3}$ (Tables 2 and 3), we believe that this $\pi-\pi$ stacking stabilization energy is not large enough to overcome the larger stability of the $\mathbf{3} T$ conformation in comparison to $3 S$, due to the inexistence of steric effects on $3 T$.

Table 5. Total energy (E), uncorrected stacking energy $\left(\Delta E^{s}\right)$, BSSE amounts and corrected stacking energy $\left(\Delta \mathrm{E}^{\mathrm{cs}}\right)$ the benzene $\cdots$ methylacrylate (Bz-MA) complex at the MPW1B95 level of theory ${ }^{a}$

\begin{tabular}{lccccc}
\hline Entry & $\mathrm{R}$ & $\mathrm{E}$ & $\Delta \mathrm{E}^{\mathrm{s}}$ & $\mathrm{BSSE}$ & $\Delta \mathrm{E}^{\mathrm{cs}}$ \\
\hline 1 & $\mathrm{MA}$ & -306.43239576 & - & - & - \\
2 & $\mathrm{Bz}$ & -232.19609799 & - & - & - \\
3 & $\mathrm{Bz} \cdots \mathrm{MA}$ & -538.63055147 & -1.3 & 0.35 & -0.95 \\
\hline
\end{tabular}

The observation that $\Delta \varepsilon_{2 S-2 T}=0.00 \mathrm{kcal} \mathrm{mol}^{-1}$ (obtained by $\mathrm{HF} / / \mathrm{HF}$ ) and $\Delta \varepsilon_{2 S-2 T}=+0.50 \mathrm{kcal} \mathrm{mol}^{-1}$ (obtained by HF// MPW1B95) points out that the steric effects on $2 T$ and $2 S$ are practically the same. Therefore the obtained value of $-0.95 \mathrm{kcal} \mathrm{mol}^{-1}$ suggests that the dispersion contribution is crucial for the relative stability of the conformation $2 S$ on the conformational equilibrium of 2 .

\section{Conclusions}

The study described in the present manuscript was performed by applying nearly two dozen different quantum chemical to calculate local minimum geometries, frequencies, thermochemical properties and ${ }^{1} \mathrm{H}$ NMR chemical shifts for (+)-8-phenylmentyl acrylate (2) and 3-phenylpropyl acrylate (3). These calculations were applied aiming to revisit the origin of the preferential $\pi-\pi$ stacking conformation of the 2 .

Based on our theoretical results we have presented more evidences that point neither Hartree-Fock nor Møller-Plesset perturbation theory (MP2) methods as able to accurately treat $\pi-\pi$ stacking interactions (respectively, underestimating and overestimating these effects).

Additionally, we have a clear proof that, differently than what were observed by Swart et al. ${ }^{14}$ the LSDA functional indeed overestimates $\pi-\pi$ stacking interaction in these molecules (2 and 3) as well as the recent DFT methods B97D, M06 and M06-2X which were developed to treat dispersion effects.

Our results from Gibbs energies and equilibrium populations for stacking and trans conformations of $\mathbf{2}$ and $\mathbf{3}$ show that the MPW1B95 is really the most suitable method to evaluate the contributions between the $\pi-\pi$ stacking and steric effects, as were reported by Moa et al. ${ }^{15}$

We believe that considering the dispersion $\pi-\pi$ stacking interactions as the only origin to the high efficiency of $\mathbf{2}$ for asymmetric reactions is not correct. Two pivotal effects (the repulsive steric and attractive $\pi-\pi$ stacking dispersion) have to be considered for the analysis of the origin of the great efficiency of $\mathbf{2}$ in asymmetric reactions.

The steric effect between the benzylic methyl group and the acrylate moiety in $\mathbf{2}$ disfavors the $\mathbf{2 T}$ conformer in comparison to $2 S$. At same time, the steric effect between phenyl and acrylate groups disfavors the $2 S$ conformation in comparison to $2 T$. These two opposite steric effects seem to be compensated by each other.

On the other hand, because of the stabilizing $\pi-\pi$ stacking intramolecular interaction between the phenyl group and acrylate moiety, the $\mathbf{2} S$ conformer is favored in comparison to $2 T$. Then, there is a balance of these two effects (dispersion and steric), favoring the $2 S$ conformation. 
The $\pi-\pi$ stacking interaction is really decisive (but not the only effect) to lead $2 S$ as the more important conformer in equilibrium of (+)-8-phenylmentyl acrylate (2).

We believe that the calculated $\pi-\pi$ stacking interaction energy for the intermolecular benzene $\cdots$ acrylate complex $4\left(-0.95 \mathrm{kcal} \mathrm{mol}^{-1}\right)$ could be used to estimate the intramolecular $\pi-\pi$ stacking interactions on $2 S$ and $3 S$. This energy is large enough to shift the conformational equilibrium to $2 S$. However, it is not strong enough to make $3 S$ conformation the most stable.

We hope that this study can provide new insights to rational design of new chiral auxiliaries for enantioselective synthesis.

\section{Supplementary Information}

Supplementary data are available free of charge at http://jbcs.sbq.org.br, as PDF file.

\section{Acknowledgments}

We would like to thank FAPESQ (Fundação de Amparo à Pesquisa do Estado da Paraíba), $\mathrm{CNPq}$ (Conselho Nacional de Desenvolvimento Científico e Tecnológico) and INCTINAMI (Instituto Nacional de Ciência e Tecnologia de Nanotecnologia para Marcadores Integrados). We also thank to G. A. U. Carvalho for reviewing our manuscript in English.

\section{References}

1. Corey, E. J.; Ensley, H. E.; J. Am. Chem. Soc. 1975, 97, 6908.

2. See In: Ager, D., Handbook of Chiral Chemicals, S. Ed.; CRC press Taylor \& Francis group : New York; T; 2006.

3. Mezrhab, B.; Dumas, F.; d'Angelo, J.; Riche, C.; J. Org. Chem. 1994, 59, 500.

4. Ulukanli, S; Karabuga, S; Celik, A.; Kazaz, C.; Tetrahedron Lett. 2005, 46, 197.

5. Actually, aliphatic molecules like long alkanes chains also involve some dispersion effect. Our analysis is approximated. Please consult the following reference for additional understanding Grime S.; Schwabe, T.; Phys. Chem. Chem. Phys. 2007, 9, 3397.

6. Hobza, P.; Phys. Chem. Chem. Phys. 2008, 10, 2581.

7. Cerný, J.; Hobza, P.; Phys. Chem. Chem. Phys. 2007, 9, 5291.

8. Zhao, Y.; Truhlar, D. G.; J. Chem. Theory Comput. 2009, 4, 1849.

9. Sinnokrot, M. O.; Sherrill, C. D.; J. Phys. Chem. A 2006, 110, 10656.

10. Hobza, P.; Selzle, H.L.; Schlag, E.W.; J. Phys. Chem. 1996, $100,18790$.
11. Tsuzuki, S.; Uchimaru, T.; Matsumura, K.; Mikami, M.; Tanabe, K.; Chem. Phys. Lett. 2000, 319, 547.

12. Zhao, Y.; Truhlar, D.; J. Chem. Theory Comput. 2005, 1, 415.

13. Zhao, Y.; Truhlar, D. G.; Acc. Chem. Res. 2008, 41, 157.

14. Swart, M.; van der Wijst, T.; Guerra, C. F.; Bickelhaupt, F. M.; J. Mol. Model. 2007, 13, 1245.

15. Moa, M. J. G.; Mandado, M.; Mosquera, R.; J. Phys. Chem. A 2007, 111, 1998.

16. Costa, P. R. R.; Cabral, L. M.; Alencar, K. G.; Schmidt, L. L.; Vasconcellos, M. L. A. A.; Tetrahedron Lett. 1997, 38, 7021.

17. Vasconcellos, M. L. A. A.; Mellão, M.; Tetrahedron: Asymmetry 1996, 7, 1607.

18. Alencar, K. G.; Dumas, F., Costa, P. R. R.; Vasconcellos, M. L. A. A.; Tetrahedron: Asymmetry 1997, 8, 579.

19. Vasconcellos, M. L. A. A.; Miranda, L. S.; Leitão, M., S. G.; Fernandes, P. D.; Marinho, B. G.; Matheus, M. E.; Bioorg. Med. Chem. Lett. 2004, 14, 1573.

20. Lima Filho, U. F.; Vasconcellos, M. L. A. A.; Pinheiro, S.; Costa, P. R. R.; Tetrahedron: Asymmetry 1994, 5, 1219.

21. de Souza, R. O. M. A.; Meireles, B. A.; Aguiar, L. C. S.; Vasconcellos, M. L. A. A.; Synthesis, 2004, 1595.

22. Filho, E. B. A.; Ventura, E.; do Monte, S. A.; Oliveira, B. G.; Junior, C. G. L.; Rocha G. B.; Vasconcellos, M. L. A. A.; Chem. Phys. Lett. 2007, 449, 336.

23. Vasconcellos, M. L. A. A.; Silva, T. M. S.; Camara, C.A.; Martins, R.M.; Lacerda, K. M.; Lopes, H. M.; Pereira, V. L. P.; de Souza, R. O. M. A.; Crespo, L.T.C.; Pest Manage.Sci. 2006, 62, 288.

24. de Souza, R. O. M. A.; Pereira, V. L. P.; Muzitano, M. F.; Falcão, C. A. B.; Rossi-Bergmann, B.; Filho, E. B. A.; Vasconcellos, M. L. A. A.; European J. Med. Chem. 2007, 42, 99.

25. Barbosa, T. P.; Junior, C. G. L.; Silva, F. P. L.; Lopes, H. M.; Figueiredo, R. L. F; Sousa, S. C. O.; Batista, G. N.; da Silva, T. G; Silva, T. M. S; Oliveira, M. R.; Vasconcellos, M. L. A. A.; European J. Med. Chem. 2009, 44, 1726.

26. Zhao, Y.; Truhlar, D. G.; J. Phys. Chem. A 2004, 108, 6908.

27. Zhao, Y.; Truhlar, D. G.; Theor. Chem. Acc. 2008, 120, 215.

28. Grimme, S.; J. Comp. Chem. 2006, 27, 1787.

29. Kohn, W.; Sham, L.; J. Phys. Rev. 1965, 140, A1133.

30. Becke, A. D.; J. Chem. Phys. 1993, 98, 5648.

31. Sousa, S. F.; Fernandes, P. A.; Ramos, M. J.; J. Phys. Chem. A, 2007, 111, 10439.

32. Grimme, S.; J. Comput. Chem. 2004, 25, 1463.

33. Becke, A. D.; Phys. Rev. A: At., Mol., Opt. Phys. 1988, $38,3098$.

34. Adamo, C.; Barone, V.; J. Chem. Phys. 1998, 108, 664.

35. Hamprecht, F. A.; Cohen, A. J.; Tozer, D. J.; Handy, N. C.; J. Chem. Phys. 1998, 109, 6264.

36. Perdew, J. P.; Burke, K.; Ernzerhof, M.; Phys. Rev. Lett. 1997, $78,1396$.

37. Lynch B. J.; Fast, P. L.; Harris, M.; Truhlar, D. G.; J. Phys. Chem. A 2000, 104, 4811. 
38. Grimme, S.; J. Chem. Phys. 2003, 118, 9095.

39. Grimme, S.; J. Comput. Chem. 2003, 24, 1529.

40. Frisch, M. J.; Trucks, G. W.; Schlegel, H. B.; Scuseria, G. E.; Robb, M. A.; Cheeseman, J. R.; Montgomery, Jr., J. A.; Vreven, T.; Kudin, K. N.; Burant, J. C.; Millam, J. M.; Iyengar, S. S.; Tomasi, J.; Barone, V.; Mennucci, B.; Cossi, M.; Scalmani, G.; Rega, N.; Petersson, G. A.; Nakatsuji, H.; Hada, M.; Ehara, M.; Toyota, K.; Fukuda, R.; Hasegawa, J.; Ishida, M.; Nakajima, T.; Honda, Y.; Kitao, O.; Nakai, H.; Klene, M.; Li, X.; Knox, J. E.; Hratchian, H. P.; Cross, J. B.; Bakken, V.; Adamo, C.; Jaramillo, J.; Gomperts, R.; Stratmann, R. E.; Yazyev, O.; Austin, A. J.; Cammi, R.; Pomelli, C.; Ochterski, J. W.; Ayala, P. Y.; Morokuma, K.; Voth, G. A.; Salvador, P.; Dannenberg, J. J.; Zakrzewski, V. G.; Dapprich, S.; Daniels, A. D.; Strain, M. C.; Farkas, O.; Malick, D. K.; Rabuck, A. D.; Raghavachari, K.; Foresman, J. B.; Ortiz, J. V.; Cui, Q.; Baboul, A. G.; Clifford, S.; Cioslowski, J.; Stefanov, B. B.; Liu, G.; Liashenko, A.; Piskorz, P.; Komaromi, I.; Martin, R. L.; Fox, D. J.; Keith, T.; Al-Laham, M. A.; Peng, C. Y.; Nanayakkara, A.; Challacombe, M.; Gill, P. M. W.; Johnson, B.; Chen, W.; Wong, M. W.; Gonzalez, C.; Pople, J. A.; Gaussian 03, Revision C.02, Gaussian, Inc., Wallingford CT, 2004.

41. Frisch, M. J.; Trucks, G. W.; Schlegel, H. B.; Scuseria, G. E.; Robb, M. A.; Cheeseman, J. R.; Scalmani, G.; Barone, V.; Mennucci, B.; Petersson, G. A.; Nakatsuji, H.; Caricato, M.; Li, X.; Hratchian, H. P.; Izmaylov, A. F.; Bloino, J.; Zheng, G.; Sonnenberg, J. L.; Hada, M.; Ehara, M.; Toyota, K.; Fukuda, R.; Hasegawa, J.; Ishida, M.; Nakajima, T.; Honda, Y.; Kitao, O.; Nakai, H.; Vreven, T.; Montgomery, Jr., J. A.; Peralta, J. E.; Ogliaro, F.; Bearpark, M.; Heyd, J. J.; Brothers, E.; Kudin, K. N.; Staroverov, V. N.; Kobayashi, R.; Normand,
J.; Raghavachari, K.; Rendell, A.; Burant, J. C.; Iyengar, S. S.; Tomasi, J.; Cossi, M.; Rega, N.; Millam, N. J.; Klene, M.; Knox, J. E.; Cross, J. B.; Bakken, V.; Adamo, C.; Jaramillo, J.; Gomperts, R.; Stratmann, R. E.; Yazyev, O.; Austin, A. J.; Cammi, R.; Pomelli, C.; Ochterski, J. W.; Martin, R. L.; Morokuma, K.; Zakrzewski, V. G.; Voth, G. A.; Salvador, P.; Dannenberg, J. J.; Dapprich, S.; Daniels, A. D.; Farkas, Ö.; Foresman, J. B.; Ortiz, J. V.; Cioslowski, J.; Fox, D. J.; Gaussian 09, Revision A.1, Gaussian, Inc., Wallingford CT, 2009.

42. Neese, F.; ORCA. An Ab Initio, Density Functional and Semiempirical Program Package, version 2.6.35L; University of Bonn: Bonn, Germany.

43. Cheeseman, J. R.; Trucks, G. W.; Keith, T. A.; Frisch, M. J.; J. Chem. Phys. 1996, 104, 5497.

44. Tomasi, J.; Mennucci, B.; Cammi, R.; Chem. Rev. 2005, 105, 2999.

45. Boys, S. F.; Bernardi, F.; Mol. Phys. 1970, 19, 553.

46. Schwenke, D. W.; Truhlar D.G.; J. Chem. Phys. 1985, 82, 2418.

47. SDBS, Spectral Database for Organic Compounds, http:// riodb01.ibase.aist.go.jp/sdbs/, accessed in July 20, 2009.

48. Kim, J. H.; Eun-Soo, P.; Shim, J. H.; Mal-Nam, K.; Woong-Sik, M.; Kyoo-Hyun, C.; Jin-San, Y.; J. Agric. Food. Chem. 2004, 52,7480 .

49. Curiously, in the Truhlar's paper (see reference 12 and 13) and quinhydrone complex calculation (see reference 15) the BSSE correction were not performed. However, we are sure that the kind of correction is pivotal to obtain accuracy of the calculation. 


\title{
Revisiting the Origin of the Preferential $\pi-\pi$ Stacking Conformation of the $(+)-8-$ Phenylmenthyl Acrylate
}

\author{
Saulo L. Capim, Sidney R. Santana, Boaz G. de Oliveira, Gerd B. Rocha* and \\ Mário L. A. A. Vasconcellos* \\ Departamento de Química, Universidade Federal da Paraíba, Campus I, \\ 58059-900 João Pessoa-PB, Brazil
}

Table S1. Cartesian coordinates and energies of HF/6-311++G(2d,2p) geometry optimized structures 2 and 3 (conformations $2 S, 2 T, 3 S$ and $3 T$ ).

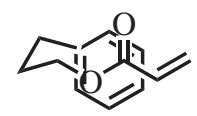

Stacking $(S)$

$3 S$

\begin{tabular}{|c|c|c|c|c|c|}
\hline \multicolumn{6}{|c|}{$\begin{array}{l}\text { Standard orientation: opt } R H F / 6-311++g(2 d, 2 p) 6 d \\
\qquad E=-612.47937340 \text { a.u. }\end{array}$} \\
\hline \multirow{2}{*}{$\begin{array}{l}\text { Center } \\
\text { Number }\end{array}$} & \multirow{2}{*}{$\begin{array}{l}\text { Atomic } \\
\text { Number }\end{array}$} & \multirow{2}{*}{$\begin{array}{l}\text { Atomic } \\
\text { Type }\end{array}$} & \multicolumn{3}{|c|}{ Coordinates (Angstroms) } \\
\hline & & & $\mathrm{X}$ & $\mathrm{Y}$ & $\mathrm{Z}$ \\
\hline 1 & 6 & 0 & 1.205188 & 1.945146 & -0.015940 \\
\hline 2 & 6 & 0 & -0.137280 & 2.498597 & -0.450446 \\
\hline 3 & 6 & 0 & -1.349391 & 2.064574 & 0.386618 \\
\hline 4 & 6 & 0 & 2.366553 & -0.088480 & -0.022114 \\
\hline 5 & 6 & 0 & 2.292837 & -1.508206 & -0.456294 \\
\hline 6 & 8 & 0 & 3.275064 & 0.398184 & 0.564463 \\
\hline 7 & 6 & 0 & 3.295279 & -2.331948 & -0.241203 \\
\hline 8 & 6 & 0 & -1.782755 & 0.621205 & 0.244542 \\
\hline 9 & 6 & 0 & -2.356035 & 0.168010 & -0.936100 \\
\hline 10 & 6 & 0 & -2.763168 & -1.143724 & -1.071673 \\
\hline 11 & 6 & 0 & -2.610096 & -2.032474 & -0.021770 \\
\hline 12 & 6 & 0 & -2.050434 & -1.592011 & 1.160281 \\
\hline 13 & 6 & 0 & -1.643202 & -0.275330 & 1.289776 \\
\hline 14 & 1 & 0 & 1.348487 & 2.041734 & 1.050826 \\
\hline 15 & 1 & 0 & 2.009272 & 2.474791 & -0.505628 \\
\hline 16 & 1 & 0 & -0.294792 & 2.262492 & -1.496072 \\
\hline 17 & 1 & 0 & -0.061957 & 3.578950 & -0.384358 \\
\hline 18 & 1 & 0 & -2.182964 & 2.699761 & 0.108767 \\
\hline 19 & 1 & 0 & -1.146249 & 2.273135 & 1.430401 \\
\hline 20 & 1 & 0 & 1.390096 & -1.815774 & -0.944390 \\
\hline 21 & 1 & 0 & 3.248347 & -3.357345 & -0.552214 \\
\hline 22 & 1 & 0 & 4.185885 & -1.995478 & 0.252300 \\
\hline 23 & 1 & 0 & -2.488522 & 0.846560 & -1.758011 \\
\hline 24 & 1 & 0 & -3.204807 & -1.471878 & -1.992862 \\
\hline 25 & 1 & 0 & -2.929383 & -3.051294 & -0.124166 \\
\hline 26 & 1 & 0 & -1.930842 & -2.268921 & 1.984078 \\
\hline 27 & 1 & 0 & -1.209951 & 0.052017 & 2.215888 \\
\hline 28 & 8 & 0 & 1.282736 & 0.574203 & -0.374292 \\
\hline
\end{tabular}

Table S2. Cartesian coordinates and energies of $\mathrm{HF} / 6-311++\mathrm{G}(2 \mathrm{~d}, 2 \mathrm{p})$ geometry optimized structures 2 and 3 (conformations $2 S, 2 T, 3 S$ and $3 T$ ).<smiles>C=CC(=O)OCC1CC1</smiles>

Trans $(T)$

$3 T$

\begin{tabular}{|c|c|c|c|c|c|}
\hline \multicolumn{6}{|c|}{$\begin{array}{l}\text { Standard orientation: opt RHF/6-311++g(2d,2p)6d } \\
\qquad E=-612.48328199 \text { a.u. }\end{array}$} \\
\hline \multirow{2}{*}{$\begin{array}{l}\text { Center } \\
\text { Number }\end{array}$} & \multirow{2}{*}{$\begin{array}{l}\text { Atomic } \\
\text { Number }\end{array}$} & \multirow{2}{*}{$\begin{array}{c}\text { Atomic } \\
\text { Type }\end{array}$} & \multicolumn{3}{|c|}{ Coordinates (Angstroms) } \\
\hline & & & $\mathrm{X}$ & Y & $\mathrm{Z}$ \\
\hline 1 & 6 & 0 & -1.391617 & 0.722918 & -0.002296 \\
\hline 2 & 6 & 0 & -0.033663 & 0.054653 & -0.000267 \\
\hline 3 & 6 & 0 & 1.100880 & 1.083531 & -0.003888 \\
\hline 4 & 6 & 0 & -3.643853 & 0.077859 & -0.000295 \\
\hline 5 & 6 & 0 & -4.556002 & -1.095844 & 0.003549 \\
\hline 6 & 8 & 0 & -3.993900 & 1.210135 & -0.004088 \\
\hline 7 & 6 & 0 & -5.861439 & -0.935776 & 0.003433 \\
\hline 8 & 6 & 0 & 2.471488 & 0.446802 & -0.001633 \\
\hline 9 & 6 & 0 & 3.111800 & 0.141229 & 1.189866 \\
\hline 10 & 6 & 0 & 4.353261 & -0.466711 & 1.194760 \\
\hline 11 & 6 & 0 & 4.978808 & -0.778992 & 0.002733 \\
\hline 12 & 6 & 0 & 4.352938 & -0.475935 & -1.191447 \\
\hline 13 & 6 & 0 & 3.111436 & 0.132050 & -1.190880 \\
\hline 14 & 1 & 0 & -1.529032 & 1.341280 & -0.877672 \\
\hline 15 & 1 & 0 & -1.528901 & 1.346849 & 0.869141 \\
\hline 16 & 1 & 0 & 0.050052 & -0.588362 & -0.868197 \\
\hline 17 & 1 & 0 & 0.050333 & -0.582573 & 0.871892 \\
\hline 18 & 1 & 0 & 1.004604 & 1.727822 & 0.862534 \\
\hline 19 & 1 & 0 & 1.004606 & 1.721675 & -0.874849 \\
\hline 20 & 1 & 0 & -4.097690 & -2.064295 & 0.006406 \\
\hline 21 & 1 & 0 & -6.524830 & -1.778501 & 0.006175 \\
\hline 22 & 1 & 0 & -6.293519 & 0.045630 & 0.000474 \\
\hline 23 & 1 & 0 & 2.639555 & 0.383780 & 2.123417 \\
\hline 24 & 1 & 0 & 4.832048 & -0.691979 & 2.128058 \\
\hline 25 & 1 & 0 & 5.943407 & -1.247769 & 0.004427 \\
\hline 26 & 1 & 0 & 4.831422 & -0.708395 & -2.123135 \\
\hline 27 & 1 & 0 & 2.638953 & 0.367385 & -2.126158 \\
\hline 28 & 8 & 0 & -2.379253 & -0.298541 & 0.001049 \\
\hline
\end{tabular}

*e-mail: mlaav@quimica.ufpb.br, gbr@quimica.ufpb.br 
Table S3. Cartesian coordinates and energies of HF/6-311++G(2d,2p) geometry optimized structures 2 and 3 (conformations $2 S, 2 T, 3 S$ and $3 T$ ).

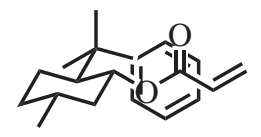

Stacking $(S)$
Table S4. Cartesian coordinates and energies of HF/6-311++G(2d,2p) geometry optimized structures 2 and 3 (conformations $2 S, 2 T, 3 S$ and $3 T$ ).

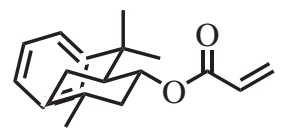

Trans $(T)$

$2 T$

\begin{tabular}{|c|c|c|c|c|c|}
\hline \multicolumn{6}{|c|}{$\begin{array}{l}\text { Standard orientation: } \mathrm{HF} / 6-311++\mathrm{G}(2 \mathrm{~d}, 2 \mathrm{p}) 6 \mathrm{~d} \\
\mathrm{E}=-884.62473753 \text { a.u. }\end{array}$} \\
\hline \multirow{2}{*}{$\begin{array}{l}\text { Center } \\
\text { Number }\end{array}$} & \multirow{2}{*}{$\begin{array}{l}\text { Atomic } \\
\text { Number }\end{array}$} & \multirow{2}{*}{$\begin{array}{l}\text { Atomic } \\
\text { Type }\end{array}$} & \multicolumn{3}{|c|}{ Coordinates (Angstroms) } \\
\hline & & & $\mathrm{X}$ & $\mathrm{Y}$ & $\mathrm{Z}$ \\
\hline 1 & 6 & 0 & 0.751393 & 1.679884 & 0.504564 \\
\hline 2 & 6 & 0 & 0.112285 & 2.956074 & -0.034386 \\
\hline 3 & 6 & 0 & -1.392536 & 2.980079 & 0.206987 \\
\hline 4 & 6 & 0 & -2.007975 & 1.708196 & -0.366647 \\
\hline 5 & 6 & 0 & -1.360612 & 0.435459 & 0.170674 \\
\hline 6 & 6 & 0 & 0.150415 & 0.393423 & -0.099328 \\
\hline 7 & 6 & 0 & 0.918924 & -0.897455 & 0.373339 \\
\hline 8 & 6 & 0 & 0.667307 & -1.179572 & 1.862422 \\
\hline 9 & 6 & 0 & 0.481660 & -2.164665 & -0.398369 \\
\hline 10 & 6 & 0 & 2.420359 & -0.704861 & 0.075366 \\
\hline 11 & 6 & 0 & 3.391935 & -0.685531 & 1.063221 \\
\hline 12 & 6 & 0 & 4.734672 & -0.525628 & 0.755933 \\
\hline 13 & 6 & 0 & 5.141074 & -0.379532 & -0.551642 \\
\hline 14 & 6 & 0 & 4.186087 & -0.398683 & -1.553071 \\
\hline 15 & 6 & 0 & 2.852850 & -0.561106 & -1.241740 \\
\hline 16 & 6 & 0 & -2.053122 & 4.229492 & -0.366427 \\
\hline 17 & 8 & 0 & -2.001121 & -0.667199 & -0.479113 \\
\hline 18 & 1 & 0 & 1.812406 & 1.708516 & 0.314225 \\
\hline 19 & 1 & 0 & 0.632879 & 1.663940 & 1.583223 \\
\hline 20 & 1 & 0 & 0.580386 & 3.816757 & 0.430950 \\
\hline 21 & 1 & 0 & 0.305965 & 3.037773 & -1.101291 \\
\hline 22 & 1 & 0 & -1.558327 & 2.978384 & 1.282224 \\
\hline 23 & 1 & 0 & -3.067140 & 1.670405 & -0.146388 \\
\hline 24 & 1 & 0 & -1.905661 & 1.711335 & -1.448246 \\
\hline 25 & 1 & 0 & -1.552999 & 0.358100 & 1.227382 \\
\hline 26 & 1 & 0 & 0.273288 & 0.452154 & -1.175752 \\
\hline 27 & 1 & 0 & 1.206474 & -2.063900 & 2.176874 \\
\hline 28 & 1 & 0 & 0.963803 & -0.363851 & 2.506582 \\
\hline 29 & 1 & 0 & -0.382267 & -1.371031 & 2.035130 \\
\hline 30 & 1 & 0 & 1.201633 & -2.954567 & -0.225727 \\
\hline 31 & 1 & 0 & 0.423821 & -1.995286 & -1.464599 \\
\hline 32 & 1 & 0 & -0.481460 & -2.517646 & -0.070018 \\
\hline 33 & 1 & 0 & 3.122153 & -0.790842 & 2.092780 \\
\hline 34 & 1 & 0 & 5.457714 & -0.515488 & 1.548762 \\
\hline 35 & 1 & 0 & 6.179127 & -0.255156 & -0.790699 \\
\hline 36 & 1 & 0 & 4.480531 & -0.289933 & -2.579211 \\
\hline 37 & 1 & 0 & 2.142767 & -0.575149 & -2.044165 \\
\hline 38 & 1 & 0 & -3.117337 & 4.239981 & -0.162035 \\
\hline 39 & 1 & 0 & -1.623909 & 5.127861 & 0.061752 \\
\hline 40 & 1 & 0 & -1.921482 & 4.280267 & -1.442183 \\
\hline 41 & 6 & 0 & -3.101857 & -1.169420 & 0.043025 \\
\hline 42 & 6 & 0 & -3.644199 & -2.264819 & -0.805177 \\
\hline 43 & 8 & 0 & -3.592030 & -0.801585 & 1.058768 \\
\hline 44 & 1 & 0 & -3.103537 & -2.495925 & -1.700880 \\
\hline 45 & 1 & 0 & -5.132483 & -3.699828 & -1.066877 \\
\hline 46 & 6 & 0 & -4.737208 & -2.909479 & -0.459045 \\
\hline 47 & 1 & 0 & -5.259847 & -2.657736 & 0.442762 \\
\hline
\end{tabular}


Table S5. Cartesian coordinates and energies of HF/6-311++G(2d,2p) geometry optimized structures 2 and 3 (conformations $2 S, 2 T, 3 S$ and $3 T$ ).

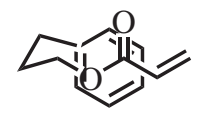

Stacking $(S)$

$3 S$

Standard orientation: opt MP2/6-311++g(2d,2p) 6d $\mathrm{E}=-614.68988216$ a.u.

\begin{tabular}{|c|c|c|c|c|c|}
\hline \multirow{2}{*}{$\begin{array}{l}\text { Center } \\
\text { Number }\end{array}$} & \multirow{2}{*}{$\begin{array}{l}\text { Atomic } \\
\text { Number }\end{array}$} & \multirow{2}{*}{$\begin{array}{l}\text { Atomic } \\
\text { Type }\end{array}$} & \multicolumn{3}{|c|}{ Coordinates (Angstroms) } \\
\hline & & & $\mathrm{X}$ & $\mathrm{Y}$ & $\mathrm{Z}$ \\
\hline 1 & 6 & 0 & -2.716864 & 0.048546 & -0.301562 \\
\hline 2 & 6 & 0 & -2.326814 & -1.413931 & -0.211465 \\
\hline 3 & 6 & 0 & -1.190743 & -1.715953 & 0.770320 \\
\hline 4 & 6 & 0 & -0.845288 & 1.478996 & 0.006501 \\
\hline 5 & 6 & 0 & 0.305841 & 2.073205 & -0.706862 \\
\hline 6 & 8 & 0 & -1.052387 & 1.546940 & 1.201535 \\
\hline 7 & 6 & 0 & 1.291319 & 2.657562 & -0.019283 \\
\hline 8 & 6 & 0 & 0.199580 & -1.283801 & 0.356375 \\
\hline 9 & 6 & 0 & 0.670988 & -1.445629 & -0.951931 \\
\hline 10 & 6 & 0 & 1.984946 & -1.116414 & -1.288035 \\
\hline 11 & 6 & 0 & 2.856300 & -0.623387 & -0.316695 \\
\hline 12 & 6 & 0 & 2.398486 & -0.451926 & 0.989797 \\
\hline 13 & 6 & 0 & 1.082658 & -0.779256 & 1.317609 \\
\hline 14 & 1 & 0 & -2.966351 & 0.452948 & 0.675748 \\
\hline 15 & 1 & 0 & -3.557250 & 0.183253 & -0.976237 \\
\hline 16 & 1 & 0 & -2.085251 & -1.783076 & -1.207425 \\
\hline 17 & 1 & 0 & -3.215832 & -1.959174 & 0.110600 \\
\hline 18 & 1 & 0 & -1.168200 & -2.794532 & 0.937968 \\
\hline 19 & 1 & 0 & -1.422735 & -1.258153 & 1.732747 \\
\hline 20 & 1 & 0 & 0.328229 & 1.979662 & -1.782053 \\
\hline 21 & 1 & 0 & 2.152363 & 3.073364 & -0.519652 \\
\hline 22 & 1 & 0 & 1.235141 & 2.713982 & 1.058140 \\
\hline 23 & 1 & 0 & 0.014336 & -1.830553 & -1.720437 \\
\hline 24 & 1 & 0 & 2.327225 & -1.251342 & -2.305060 \\
\hline 25 & 1 & 0 & 3.874938 & -0.370816 & -0.576051 \\
\hline 26 & 1 & 0 & 3.061349 & -0.064754 & 1.751569 \\
\hline 27 & 1 & 0 & 0.728643 & -0.628314 & 2.329235 \\
\hline 28 & 8 & 0 & -1.643744 & 0.824238 & -0.873748 \\
\hline
\end{tabular}

Table S6. Cartesian coordinates and energies of MP2/6-311++G(2d,2p) geometry optimized structures 3 (conformations $3 S$ and $3 T$ ).

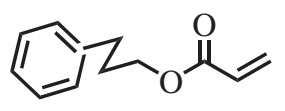

Trans $(T)$

$3 T$

Standard orientation: opt MP2/6-311++g(2d,2p) $6 \mathrm{~d}$ $\mathrm{E}=-614.68553739$ a.u.

\begin{tabular}{|c|c|c|c|c|c|}
\hline \multirow{2}{*}{$\begin{array}{l}\text { Center } \\
\text { Number }\end{array}$} & \multirow{2}{*}{$\begin{array}{l}\text { Atomic } \\
\text { Number }\end{array}$} & \multirow{2}{*}{$\begin{array}{l}\text { Atomic } \\
\text { Type }\end{array}$} & \multicolumn{3}{|c|}{ Coordinates (Angstroms) } \\
\hline & & & $\mathrm{X}$ & Y & Z \\
\hline 1 & 6 & 0 & 1.375147 & 0.702327 & -0.007998 \\
\hline 2 & 6 & 0 & 0.008177 & 0.060489 & -0.000146 \\
\hline 3 & 6 & 0 & -1.100321 & 1.116671 & -0.013442 \\
\hline 4 & 6 & 0 & 3.639497 & 0.061496 & -0.000637 \\
\hline 5 & 6 & 0 & 4.562645 & -1.099159 & 0.014014 \\
\hline 6 & 8 & 0 & 3.967100 & 1.230525 & -0.016015 \\
\hline 7 & 6 & 0 & 5.884445 & -0.908442 & 0.010781 \\
\hline 8 & 6 & 0 & -2.463867 & 0.481861 & -0.005976 \\
\hline 9 & 6 & 0 & -3.098174 & 0.137680 & -1.204154 \\
\hline 10 & 6 & 0 & -4.338250 & -0.500960 & -1.200654 \\
\hline 11 & 6 & 0 & -4.962356 & -0.806667 & 0.009285 \\
\hline 12 & 6 & 0 & -4.340936 & -0.467193 & 1.211566 \\
\hline 13 & 6 & 0 & -3.100842 & 0.171344 & 1.199942 \\
\hline 14 & 1 & 0 & 1.530383 & 1.334744 & 0.864259 \\
\hline 15 & 1 & 0 & 1.530650 & 1.312681 & -0.895779 \\
\hline 16 & 1 & 0 & -0.096586 & -0.567407 & 0.884159 \\
\hline 17 & 1 & 0 & -0.096358 & -0.589246 & -0.868557 \\
\hline 18 & 1 & 0 & -0.992739 & 1.745930 & -0.898178 \\
\hline 19 & 1 & 0 & -0.993226 & 1.767527 & 0.855580 \\
\hline 20 & 1 & 0 & 4.122752 & -2.084919 & 0.027130 \\
\hline 21 & 1 & 0 & 6.569511 & -1.741830 & 0.021278 \\
\hline 22 & 1 & 0 & 6.283642 & 0.095198 & -0.002546 \\
\hline 23 & 1 & 0 & -2.620742 & 0.378134 & -2.146138 \\
\hline 24 & 1 & 0 & -4.816381 & -0.754615 & -2.136514 \\
\hline 25 & 1 & 0 & -5.924691 & -1.298413 & 0.015101 \\
\hline 26 & 1 & 0 & -4.821145 & -0.694573 & 2.153098 \\
\hline 27 & 1 & 0 & -2.625477 & 0.438079 & 2.135872 \\
\hline 28 & 8 & 0 & 2.352826 & -0.360270 & 0.005483 \\
\hline
\end{tabular}


Table S7. Cartesian coordinates and energies of MP2/6-311++G(2d,2p) geometry optimized structures 3 (conformations $3 S$ and $3 T$ ).

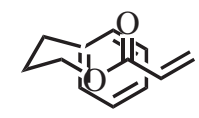

Stacking $(S)$

$3 S$

Standard orientation: opt MPWB95/6-311++g(2d,2p) 6d $\operatorname{iop}(3 / 76=0690003100)$ $\mathrm{E}=-616.04311982$ a.u.

\begin{tabular}{|c|c|c|c|c|c|}
\hline \multirow{2}{*}{$\begin{array}{l}\text { Center } \\
\text { Number }\end{array}$} & \multirow{2}{*}{$\begin{array}{l}\text { Atomic } \\
\text { Number }\end{array}$} & \multirow{2}{*}{$\begin{array}{l}\text { Atomic } \\
\text { Type }\end{array}$} & \multicolumn{3}{|c|}{ Coordinates (Angstroms) } \\
\hline & & & $\mathrm{X}$ & $\mathrm{Y}$ & $\mathrm{Z}$ \\
\hline 1 & 6 & 0 & -2.609503 & -0.405898 & -0.299849 \\
\hline 2 & 6 & 0 & -2.009479 & -1.789759 & -0.232784 \\
\hline 3 & 6 & 0 & -0.862739 & -1.946122 & 0.758964 \\
\hline 4 & 6 & 0 & -1.106478 & 1.396528 & -0.012543 \\
\hline 5 & 6 & 0 & -0.126584 & 2.233052 & -0.727717 \\
\hline 6 & 8 & 0 & -1.358837 & 1.470921 & 1.160490 \\
\hline 7 & 6 & 0 & 0.581035 & 3.135353 & -0.071208 \\
\hline 8 & 6 & 0 & 0.456107 & -1.333726 & 0.368475 \\
\hline 9 & 6 & 0 & 0.988534 & -1.475937 & -0.906323 \\
\hline 10 & 6 & 0 & 2.219681 & -0.934492 & -1.227611 \\
\hline 11 & 6 & 0 & 2.947549 & -0.242328 & -0.276311 \\
\hline 12 & 6 & 0 & 2.430956 & -0.096562 & 0.997466 \\
\hline 13 & 6 & 0 & 1.197545 & -0.636920 & 1.311928 \\
\hline 14 & 1 & 0 & -2.912375 & -0.057986 & 0.683009 \\
\hline 15 & 1 & 0 & -3.467736 & -0.395475 & -0.965527 \\
\hline 16 & 1 & 0 & -1.701191 & -2.096138 & -1.230878 \\
\hline 17 & 1 & 0 & -2.814236 & -2.465274 & 0.057256 \\
\hline 18 & 1 & 0 & -0.705140 & -3.012612 & 0.926260 \\
\hline 19 & 1 & 0 & -1.166187 & -1.529154 & 1.718700 \\
\hline 20 & 1 & 0 & -0.013561 & 2.059479 & -1.785685 \\
\hline 21 & 1 & 0 & 1.312288 & 3.751685 & -0.568765 \\
\hline 22 & 1 & 0 & 0.435541 & 3.263562 & 0.990664 \\
\hline 23 & 1 & 0 & 0.437702 & -2.013711 & -1.663359 \\
\hline 24 & 1 & 0 & 2.612383 & -1.056223 & -2.225615 \\
\hline 25 & 1 & 0 & 3.907607 & 0.180851 & -0.527767 \\
\hline 26 & 1 & 0 & 2.984908 & 0.445660 & 1.748303 \\
\hline 27 & 1 & 0 & 0.788587 & -0.498199 & 2.301736 \\
\hline 28 & 8 & 0 & -1.683455 & 0.529630 & -0.854647 \\
\hline
\end{tabular}

Table S8. Cartesian coordinates and energies of MPW1B95/6$311++\mathrm{G}(2 \mathrm{~d}, 2 \mathrm{p})$ geometry optimized structures 2 and 3 ( conformations $\mathbf{2 S}, \mathbf{2 T}, \mathbf{3 S}$ and $\mathbf{3 T}$ ).

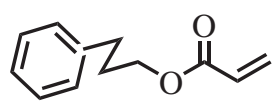

Trans (T)

$3 T$

\begin{tabular}{|c|c|c|c|c|c|}
\hline \multicolumn{6}{|c|}{$\begin{array}{c}\text { Standard orientation: opt MPWB95/6 }-311++\mathrm{g}(2 \mathrm{~d}, 2 \mathrm{p}) 6 \mathrm{~d} \\
\operatorname{iop}(3 / 76=0690003100) \\
\mathrm{E}=-616.04509962 \text { a.u. }\end{array}$} \\
\hline \multirow{2}{*}{$\begin{array}{l}\text { Center } \\
\text { Number }\end{array}$} & \multirow{2}{*}{$\begin{array}{l}\text { Atomic } \\
\text { Number }\end{array}$} & \multirow{2}{*}{$\begin{array}{l}\text { Atomic } \\
\text { Type }\end{array}$} & \multicolumn{3}{|c|}{ Coordinates (Angstroms) } \\
\hline & & & $\mathrm{X}$ & $\mathrm{Y}$ & $\mathrm{Z}$ \\
\hline 1 & 6 & 0 & 1.378431 & -0.519547 & -0.439116 \\
\hline 2 & 6 & 0 & 0.021948 & 0.050079 & -0.124766 \\
\hline 3 & 6 & 0 & -1.090115 & -0.836749 & -0.671428 \\
\hline 4 & 6 & 0 & 3.627879 & -0.063060 & -0.019085 \\
\hline 5 & 6 & 0 & 4.568974 & 0.903826 & 0.577835 \\
\hline 6 & 8 & 0 & 3.933895 & -1.096864 & -0.549874 \\
\hline 7 & 6 & 0 & 5.867413 & 0.656882 & 0.574700 \\
\hline 8 & 6 & 0 & -2.454908 & -0.352406 & -0.283084 \\
\hline 9 & 6 & 0 & -3.128323 & -0.931211 & 0.782341 \\
\hline 10 & 6 & 0 & -4.372039 & -0.470619 & 1.175088 \\
\hline 11 & 6 & 0 & -4.965169 & 0.580915 & 0.502012 \\
\hline 12 & 6 & 0 & -4.306147 & 1.165137 & -0.565624 \\
\hline 13 & 6 & 0 & -3.062363 & 0.701394 & -0.952646 \\
\hline 14 & 1 & 0 & 1.544481 & -0.612023 & -1.510983 \\
\hline 15 & 1 & 0 & 1.510061 & -1.508845 & -0.005227 \\
\hline 16 & 1 & 0 & -0.062110 & 1.052256 & -0.541922 \\
\hline 17 & 1 & 0 & -0.085401 & 0.148595 & 0.954170 \\
\hline 18 & 1 & 0 & -0.953501 & -1.851305 & -0.298211 \\
\hline 19 & 1 & 0 & -1.011081 & -0.891196 & -1.757128 \\
\hline 20 & 1 & 0 & 4.147038 & 1.798497 & 1.007510 \\
\hline 21 & 1 & 0 & 6.575370 & 1.346313 & 1.005589 \\
\hline 22 & 1 & 0 & 6.239944 & -0.255135 & 0.133099 \\
\hline 23 & 1 & 0 & -2.672705 & -1.756484 & 1.310448 \\
\hline 24 & 1 & 0 & -4.879407 & -0.935899 & 2.006084 \\
\hline 25 & 1 & 0 & -5.936618 & 0.941377 & 0.802291 \\
\hline 26 & 1 & 0 & -4.763916 & 1.981861 & -1.102385 \\
\hline 27 & 1 & 0 & -2.557465 & 1.159364 & -1.791532 \\
\hline 28 & 8 & 0 & 2.365083 & 0.356211 & 0.106228 \\
\hline
\end{tabular}


Table S9. Cartesian coordinates and energies of MPW1B95/6$311++\mathrm{G}(2 \mathrm{~d}, 2 \mathrm{p}$ ) geometry optimized structures 2 and 3 ( conformations $\mathbf{2 S}, \mathbf{2 T}, \mathbf{3} S$ and $\mathbf{3 T}$ ).

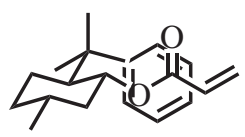

Stacking $(S)$
Table S10. Cartesian coordinates and energies of MPW1B95/6$311++\mathrm{G}(2 \mathrm{~d}, 2 \mathrm{p})$ geometry optimized structures 2 and 3 ( conformations $\mathbf{2 S}, \mathbf{2 T}, \mathbf{3 S}$ and $\mathbf{3 T}$ ).

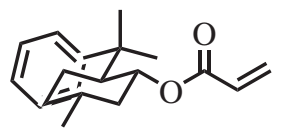

Trans $(T)$

$2 T$

Standard orientation: opt MPWB95/6-311++g(2d,2p) 6d $\operatorname{iop}(3 / 76=0690003100)$

$\mathrm{E}=-889.95725590$ a.u.

\begin{tabular}{|c|c|c|c|c|c|}
\hline \multirow{2}{*}{$\begin{array}{l}\text { Center } \\
\text { Number }\end{array}$} & \multirow{2}{*}{$\begin{array}{l}\text { Atomic } \\
\text { Number }\end{array}$} & \multirow{2}{*}{$\begin{array}{l}\text { Atomic } \\
\text { Type }\end{array}$} & \multicolumn{3}{|c|}{ Coordinates (Angstroms) } \\
\hline & & & $\mathrm{X}$ & $\mathrm{Y}$ & $\mathrm{Z}$ \\
\hline 1 & 6 & 0 & 2.331005 & -1.627212 & 0.455650 \\
\hline 2 & 6 & 0 & 3.507622 & -1.130442 & -0.366033 \\
\hline 3 & 6 & 0 & 3.653796 & 0.378438 & -0.308342 \\
\hline 4 & 6 & 0 & 2.343372 & 1.014901 & -0.735864 \\
\hline 5 & 6 & 0 & 1.189533 & 0.522705 & 0.108701 \\
\hline 6 & 6 & 0 & 1.010548 & -0.984163 & 0.034725 \\
\hline 7 & 6 & 0 & -0.218328 & -1.500643 & 0.842150 \\
\hline 8 & 6 & 0 & -0.132532 & -3.021380 & 1.019936 \\
\hline 9 & 6 & 0 & -0.238204 & -0.878701 & 2.232940 \\
\hline 10 & 6 & 0 & -1.515384 & -1.228604 & 0.086112 \\
\hline 11 & 6 & 0 & -1.690385 & -1.733447 & -1.198849 \\
\hline 12 & 6 & 0 & -2.867359 & -1.543190 & -1.895247 \\
\hline 13 & 6 & 0 & -3.913868 & -0.845043 & -1.317764 \\
\hline 14 & 6 & 0 & -3.761782 & -0.346477 & -0.039299 \\
\hline 15 & 6 & 0 & -2.577049 & -0.537811 & 0.651888 \\
\hline 16 & 6 & 0 & 4.811959 & 0.868937 & -1.154230 \\
\hline 17 & 8 & 0 & -0.011678 & 1.149651 & -0.358136 \\
\hline 18 & 1 & 0 & 2.261577 & -2.706405 & 0.357936 \\
\hline 19 & 1 & 0 & 2.517015 & -1.421030 & 1.512003 \\
\hline 20 & 1 & 0 & 4.424885 & -1.609965 & -0.025842 \\
\hline 21 & 1 & 0 & 3.370578 & -1.426568 & -1.409313 \\
\hline 22 & 1 & 0 & 3.840484 & 0.659440 & 0.731871 \\
\hline 23 & 1 & 0 & 2.398303 & 2.099639 & -0.657332 \\
\hline 24 & 1 & 0 & 2.144420 & 0.773277 & -1.782194 \\
\hline 25 & 1 & 0 & 1.351799 & 0.830703 & 1.138932 \\
\hline 26 & 1 & 0 & 0.846639 & -1.237400 & -1.014861 \\
\hline 27 & 1 & 0 & -1.065259 & -3.391368 & 1.437935 \\
\hline 28 & 1 & 0 & 0.032505 & -3.530182 & 0.072396 \\
\hline 29 & 1 & 0 & 0.671270 & -3.294853 & 1.698859 \\
\hline 30 & 1 & 0 & -1.011603 & -1.337774 & 2.844414 \\
\hline 31 & 1 & 0 & -0.416427 & 0.193592 & 2.212433 \\
\hline 32 & 1 & 0 & 0.713517 & -1.047652 & 2.731845 \\
\hline 33 & 1 & 0 & -0.892623 & -2.289475 & -1.668868 \\
\hline 34 & 1 & 0 & -2.969550 & -1.945180 & -2.891741 \\
\hline 35 & 1 & 0 & -4.835826 & -0.696858 & -1.858107 \\
\hline 36 & 1 & 0 & -4.566671 & 0.199725 & 0.428417 \\
\hline 37 & 1 & 0 & -2.488863 & -0.126661 & 1.643985 \\
\hline 38 & 1 & 0 & 4.918019 & 1.949771 & -1.093272 \\
\hline 39 & 1 & 0 & 5.750612 & 0.420917 & -0.835093 \\
\hline 40 & 1 & 0 & 4.658769 & 0.608365 & -2.200880 \\
\hline 41 & 6 & 0 & -0.460660 & 2.212812 & 0.312062 \\
\hline 42 & 6 & 0 & -1.690968 & 2.736291 & -0.312544 \\
\hline 43 & 8 & 0 & 0.067027 & 2.671449 & 1.292019 \\
\hline 44 & 1 & 0 & -2.069952 & 2.197855 & -1.166271 \\
\hline 45 & 1 & 0 & -3.178163 & 4.215578 & -0.264265 \\
\hline 46 & 6 & 0 & -2.279285 & 3.814588 & 0.175675 \\
\hline 47 & 1 & 0 & -1.860438 & 4.314354 & 1.035933 \\
\hline
\end{tabular}

Standard orientation: opt MPWB95/6-311++g(2d,2p) 6d $\operatorname{iop}(3 / 76=0690003100)$

$\mathrm{E}=-889.95629860$ a.u.

\begin{tabular}{|c|c|c|c|c|c|}
\hline \multirow{2}{*}{$\begin{array}{l}\text { Center } \\
\text { Number }\end{array}$} & \multirow{2}{*}{$\begin{array}{l}\text { Atomic } \\
\text { Number }\end{array}$} & \multirow{2}{*}{$\begin{array}{c}\text { Atomic } \\
\text { Type }\end{array}$} & \multicolumn{3}{|c|}{ Coordinates (Angstroms) } \\
\hline & & & $\mathrm{X}$ & $\mathrm{Y}$ & $\mathrm{Z}$ \\
\hline 1 & 6 & 0 & 0.821841 & 1.591542 & 0.398574 \\
\hline 2 & 6 & 0 & 0.205070 & 2.908760 & -0.031916 \\
\hline 3 & 6 & 0 & -1.282062 & 2.963247 & 0.261273 \\
\hline 4 & 6 & 0 & -1.948187 & 1.760405 & -0.380121 \\
\hline 5 & 6 & 0 & -1.318472 & 0.461235 & 0.074057 \\
\hline 6 & 6 & 0 & 0.161885 & 0.379122 & -0.262641 \\
\hline 7 & 6 & 0 & 0.856243 & -0.963863 & 0.133734 \\
\hline 8 & 6 & 0 & 0.429509 & -1.396728 & 1.530168 \\
\hline 9 & 6 & 0 & 0.497517 & -2.099024 & -0.834413 \\
\hline 10 & 6 & 0 & 2.364530 & -0.767029 & 0.038666 \\
\hline 11 & 6 & 0 & 3.204442 & -0.821085 & 1.140957 \\
\hline 12 & 6 & 0 & 4.571130 & -0.629263 & 1.013264 \\
\hline 13 & 6 & 0 & 5.128850 & -0.375028 & -0.223285 \\
\hline 14 & 6 & 0 & 4.304665 & -0.315095 & -1.334140 \\
\hline 15 & 6 & 0 & 2.944506 & -0.510268 & -1.200794 \\
\hline 16 & 6 & 0 & -1.910956 & 4.260598 & -0.206043 \\
\hline 17 & 8 & 0 & -2.024237 & -0.619795 & -0.557264 \\
\hline 18 & 1 & 0 & 1.882937 & 1.595474 & 0.172637 \\
\hline 19 & 1 & 0 & 0.738811 & 1.492783 & 1.483582 \\
\hline 20 & 1 & 0 & 0.716865 & 3.735352 & 0.459822 \\
\hline 21 & 1 & 0 & 0.355207 & 3.044860 & -1.106137 \\
\hline 22 & 1 & 0 & -1.414830 & 2.882377 & 1.343562 \\
\hline 23 & 1 & 0 & -3.009211 & 1.733772 & -0.137528 \\
\hline 24 & 1 & 0 & -1.860748 & 1.831997 & -1.466523 \\
\hline 25 & 1 & 0 & -1.454966 & 0.362341 & 1.148696 \\
\hline 26 & 1 & 0 & 0.265505 & 0.489956 & -1.345795 \\
\hline 27 & 1 & 0 & 0.974094 & -2.286609 & 1.836911 \\
\hline 28 & 1 & 0 & 0.597187 & -0.624719 & 2.278399 \\
\hline 29 & 1 & 0 & -0.629006 & -1.644158 & 1.538751 \\
\hline 30 & 1 & 0 & 1.156006 & -2.947012 & -0.659990 \\
\hline 31 & 1 & 0 & 0.614726 & -1.794619 & -1.871350 \\
\hline 32 & 1 & 0 & -0.524794 & -2.428098 & -0.698504 \\
\hline 33 & 1 & 0 & 2.798769 & -1.011082 & 2.121180 \\
\hline 34 & 1 & 0 & 5.198865 & -0.678559 & 1.889876 \\
\hline 35 & 1 & 0 & 6.192477 & -0.225508 & -0.323625 \\
\hline 36 & 1 & 0 & 4.723789 & -0.116873 & -2.308800 \\
\hline 37 & 1 & 0 & 2.320278 & -0.456402 & -2.080025 \\
\hline 38 & 1 & 0 & -2.973936 & 4.291895 & 0.022887 \\
\hline 39 & 1 & 0 & -1.439864 & 5.119335 & 0.267453 \\
\hline 40 & 1 & 0 & -1.799235 & 4.373568 & -1.283932 \\
\hline 41 & 6 & 0 & -3.098297 & -1.092146 & 0.081383 \\
\hline 42 & 6 & 0 & -3.729225 & -2.179898 & -0.692510 \\
\hline 43 & 8 & 0 & -3.485592 & -0.688779 & 1.146166 \\
\hline 44 & 1 & 0 & -3.276335 & -2.435603 & -1.637432 \\
\hline 45 & 1 & 0 & -5.275618 & -3.596385 & -0.770898 \\
\hline 46 & 6 & 0 & -4.799854 & -2.797937 & -0.224725 \\
\hline 47 & 1 & 0 & -5.217154 & -2.504755 & 0.726639 \\
\hline
\end{tabular}


Table S11. Cartesian coordinates and energies of MPW1B95/6$311++\mathrm{G}(2 \mathrm{~d}, 2 \mathrm{p})$ geometry optimized structures 2 and 3 ( conformations $2 S, 2 T, 3 S$ and $3 T$ ).

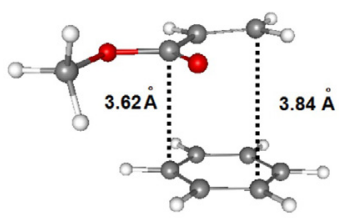

4

Standard orientation: opt MPWB95/6-311++g(2d,2p) 6d $\operatorname{iop}(3 / 76=0690003100)$

$\mathrm{E}=-538.63055147$ a.u.

\begin{tabular}{|c|c|c|c|c|c|}
\hline \multirow{2}{*}{$\begin{array}{l}\text { Center } \\
\text { Number }\end{array}$} & \multirow{2}{*}{$\begin{array}{l}\text { Atomic } \\
\text { Number }\end{array}$} & \multirow{2}{*}{$\begin{array}{l}\text { Atomic } \\
\text { Type }\end{array}$} & \multicolumn{3}{|c|}{ Coordinates (Angstroms) } \\
\hline & & & $\mathrm{X}$ & $\mathrm{Y}$ & $\mathrm{Z}$ \\
\hline 1 & 6 & 0 & -3.051402 & -1.352407 & -0.011567 \\
\hline 2 & 6 & 0 & -1.711069 & 0.543924 & -0.002474 \\
\hline 3 & 6 & 0 & -0.881434 & 1.435478 & -0.830656 \\
\hline 4 & 8 & 0 & -1.912665 & 0.663865 & 1.176038 \\
\hline 5 & 6 & 0 & -0.309025 & 2.498546 & -0.294047 \\
\hline 6 & 8 & 0 & -2.232194 & -0.447186 & -0.736330 \\
\hline 7 & 1 & 0 & -3.893472 & -0.830604 & 0.432357 \\
\hline 8 & 1 & 0 & -3.392957 & -2.086629 & -0.729660 \\
\hline 9 & 1 & 0 & -2.481858 & -1.828228 & 0.781063 \\
\hline 10 & 1 & 0 & -0.763621 & 1.170501 & -1.868951 \\
\hline 11 & 1 & 0 & 0.308695 & 3.162493 & -0.876644 \\
\hline 12 & 1 & 0 & -0.450999 & 2.713996 & 0.754138 \\
\hline 13 & 6 & 0 & 0.965065 & -1.304899 & 0.799157 \\
\hline 14 & 6 & 0 & 1.199605 & -1.542082 & -0.543669 \\
\hline 15 & 6 & 0 & 2.129853 & -0.779156 & -1.228682 \\
\hline 16 & 6 & 0 & 2.825814 & 0.217782 & -0.569072 \\
\hline 17 & 6 & 0 & 2.590012 & 0.454514 & 0.774096 \\
\hline 18 & 6 & 0 & 1.655620 & -0.303000 & 1.457294 \\
\hline 19 & 1 & 0 & 0.235547 & -1.893598 & 1.333474 \\
\hline 20 & 1 & 0 & 0.656612 & -2.320164 & -1.057517 \\
\hline 21 & 1 & 0 & 2.313812 & -0.964411 & -2.275780 \\
\hline 22 & 1 & 0 & 3.554326 & 0.810019 & -1.101253 \\
\hline 23 & 1 & 0 & 3.132793 & 1.233051 & 1.287800 \\
\hline 24 & 1 & 0 & 1.461752 & -0.112047 & 2.501026 \\
\hline
\end{tabular}

Table S12. Cartesian coordinates and energies of MPW1B95/6$311++\mathrm{G}(2 \mathrm{~d}, 2 \mathrm{p})$ geometry optimized structures to the complex 4 .

BENZENE

\begin{tabular}{|c|c|c|c|c|c|}
\hline \multicolumn{6}{|c|}{ ENZENE } \\
\hline \multicolumn{6}{|c|}{$\begin{array}{l}\text { Standard orientation: opt MPWB95/6-311++g(2d,2p) 6d } \\
\qquad \begin{array}{c}\operatorname{iop}(3 / 76=0690003100) \\
E=-232.19609986\end{array}\end{array}$} \\
\hline \multirow{2}{*}{$\begin{array}{l}\text { Center } \\
\text { Number }\end{array}$} & \multirow{2}{*}{$\begin{array}{l}\text { Atomic } \\
\text { Number }\end{array}$} & \multirow{2}{*}{$\begin{array}{l}\text { Atomic } \\
\text { Type }\end{array}$} & \multicolumn{3}{|c|}{ Coordinates (Angstroms) } \\
\hline & & & $\mathrm{X}$ & Y & Z \\
\hline 1 & 6 & 0 & -0.215622 & 1.366749 & 0.000000 \\
\hline 2 & 6 & 0 & -1.291600 & 0.496640 & -0.000011 \\
\hline 3 & 6 & 0 & -1.076046 & -0.870020 & 0.000011 \\
\hline 4 & 6 & 0 & 0.215634 & -1.366748 & -0.000001 \\
\hline 5 & 6 & 0 & 1.291596 & -0.496651 & -0.000010 \\
\hline 6 & 6 & 0 & 1.076038 & 0.870030 & 0.000008 \\
\hline 7 & 1 & 0 & -0.384603 & 2.432500 & 0.000006 \\
\hline 8 & 1 & 0 & -2.299044 & 0.883216 & -0.000010 \\
\hline 9 & 1 & 0 & -1.914544 & -1.549198 & 0.000014 \\
\hline 10 & 1 & 0 & 0.384583 & -2.432503 & 0.000000 \\
\hline 11 & 1 & 0 & 2.299051 & -0.883197 & -0.000003 \\
\hline 12 & 1 & 0 & 1.914557 & 1.549182 & 0.000011 \\
\hline
\end{tabular}

Table S13. Cartesian coordinates and energies of MPW1B95/6$311++\mathrm{G}(2 \mathrm{~d}, 2 \mathrm{p})$ geometry optimized structures to the complex 4 .

\section{METHYL ACRYLATE}

Standard orientation: opt MPWB95/6-311++g(2d,2p) 6d $\operatorname{iop}(3 / 76=0690003100)$

$\mathrm{E}=-306.43239576$ a.u.

\begin{tabular}{cccccc}
\hline \multirow{2}{*}{$\begin{array}{c}\text { Center } \\
\text { Number }\end{array}$} & $\begin{array}{c}\text { Atomic } \\
\text { Number }\end{array}$ & $\begin{array}{c}\text { Atomic } \\
\text { Type }\end{array}$ & \multicolumn{3}{c}{ Coordinates (Angstroms) } \\
\cline { 4 - 6 } & & & $\mathrm{X}$ & $\mathrm{Y}$ & $\mathrm{Z}$ \\
\hline 1 & 6 & 0 & -0.040557 & 0.105756 & -0.000047 \\
2 & 6 & 0 & -1.310024 & -0.644225 & -0.000044 \\
3 & 1 & 0 & -1.244640 & -1.720576 & -0.000118 \\
4 & 6 & 0 & -2.462937 & 0.001994 & 0.000059 \\
5 & 1 & 0 & -2.473278 & 1.081509 & 0.000132 \\
6 & 1 & 0 & -3.405133 & -0.521743 & 0.000069 \\
7 & 6 & 0 & 2.274613 & -0.078066 & 0.000043 \\
8 & 1 & 0 & 2.380204 & 0.545210 & 0.882364 \\
9 & 1 & 0 & 3.012300 & -0.869703 & 0.000133 \\
10 & 1 & 0 & 2.380313 & 0.545106 & -0.882339 \\
11 & 8 & 0 & 1.008010 & -0.724008 & 0.000001 \\
12 & 8 & 0 & 0.064948 & 1.302438 & -0.000040 \\
\hline
\end{tabular}

